\title{
Ciências da Comunicação
}

\section{O Relatório MacBride e a gênese do debate internacional sobre trocas desiguais nas indústrias de comunicação'}

The MacBride Report and the Genesis of the international debate upon the unequal exchanges in communication industries

JOÃO MARTINS LADEIRA

Pesquisador associado aos grupos Unisinos Cepos e lesp Netsal. <joaomartinsladeira@gmail.com>

\section{RESUMO}

Por meio de um diálogo entre estudos de cidadania, economia política da comunicação e teoria da estruturação, este artigo analisa os argumentos através dos quais se construiu a intensa atenção internacional à proposta de democratização da comunicação e às trocas desiguais nas indústrias culturais. Durante os anos 70, tal assunto conquistou a agenda de debates, produzindo como ponto alto o Relatório MacBride. Este artigo se concentra em tal texto. No trabalho interpretam-se seus argumentos como uma tentativa de definir o desenvolvimento em termos de um problema capaz de ultrapassar o âmbito técnico ou econômico, transformando-se na defesa de um direito e, por fim analisa-se a construção de tal visão com ênfase na apropriação do princípio de igualdade intrínseco à cidadania como recurso voltado à legitimação de tais ideias.

Palavras-chave: Estudos de cidadania; Democratização da comunicação; Economia política da comunicação; Teoria da estruturação.

\begin{abstract}
Towards a dialogue between the studies of citizenship, the political economy of communication and the structuration theory, this article analysis the arguments through which have been constituted an intense international attention to the idea of democratization of communication and unequal exchanges in cultural industries. During the 70s, that subject conquered the agenda of debates, producing, as its apex, the MacBride Report. This article concentrates at this text. It interprets those arguments as an attempt to define development as a problem far-reaching the technical or economic sphere, turning itself as the defense of a right. It analysis the construction of such vision, with emphasis at the appropriation of the principle of equality intrinsic to citizenship as a resource oriented towards the legitimating of this idea.

Keywords: Citizenships studies; Democratization of communication; Political economy of communication; Structuration theory
\end{abstract}


$\mathrm{D}$ urante os anos 70, um intenso debate sobre a desigualdade entre estruturas de comunicação de países desenvolvidos e subdesenvolvidos despontou na agenda mundial, tornando-se elemento de primeira importância. Agências internacionais, entre as quais se destacavam as Nações Unidas e especialmente a Unesco, serviram de arena para a disputa. Afirmar um direito social pontual, a democratização da comunicação, era o resultado mais relevante daquele processo. Em tal debate, Estados específicos apontavam a necessidade de, com base neste conjunto recém-imaginado de direitos, introduzir novas pautas nas relações entre nações. As desigualdades entre países e as limitações à livre expressão humana se conectavam em argumentos capazes de associar questões econômicas e valores morais, produzindo abordagens responsáveis por politizar intensamente a forma pela qual se encaram tais indústrias de comunicação. A construção de um consenso sobre a relevância destes direitos será o tema deste artigo.

A fim de contribuir com o debate, este trabalho concentra-se no Relatório MacBride (Unesco, [1980] 1983), ponto alto de um conjunto prévio de questionamentos 2. A intervenção da Unesco, suas motivações, suas consequências e as razões de seu fracasso já foram anteriormente documentadas (Carlsson, 2003; Mastrini e Charras, 2005; Pasquali, 2005). O objetivo deste texto reside não em retomar tal histórico, mas em propor, por meio do diálogo entre a economia política da comunicação (Mosco, 2009), o debate sobre cidadania (Marshall, 1967) e a teoria da estruturação (Giddens, [1984] 1989), uma leitura sobre tal momento.

Interpreta-se o esforço em construir um interesse global sobre o tema da comunicação como trabalho político complexo. Entender a instituição de tais ideias possui extrema importância. Identifica-se a origem de sua força na capacidade de afirmar a troca desigual como um processo endógeno ao capitalismo, legitimando um entendimento sobre tais relações comerciais como mais que meras transações 
econômicas; constituindo-se como a violação de um direito social à comunicação. Como resultado, oferece-se um novo nível de importância à desigualdade entre Estados. Após tal proposta se consolidar, a expectativa de um conjunto de países especialmente as nações do terceiro mundo - em se afirmar na política internacional passa a dispor de outro elemento a ser monitorado, reflexivamente no relacionamento entre Estados.

Durante o trabalho de legitimar a autoridade que esperou estabelecer, o Relatório MacBride se refere, continuamente, a valores decorrentes das noções de cidadania e de direito à participação integral, por meio do princípio da igualdade, no legado produzido pela modernidade. Aqui, os instrumentos de política internacional mostram intensa importância. A ênfase nas desigualdades percebidas em relação a países de terceiro mundo, com atenção aos Estados formados após o processo de descolonização, transforma a Unesco em uma instância privilegiada de discussão, e o Relatório no melhor exemplo de seu projeto. A atuação de tal organização torna questões de desenvolvimento econômico em mais do que um assunto técnico. Não somente um problema possível de solucionar através da aplicação correta de investimentos, as trocas desiguais nas indústrias de comunicação se tornam a violação de um conjunto de direitos sociais, impedindo o exercício de certas necessidades fundamentais.

Em contraponto, o Relatório MacBride propunha produzir uma "Nova Ordem Mundial de Comunicação e Informação", processo de criatividade social votado a afirmar novas visões de mundo. No interesse de compreender tal movimento, este artigo se divide em três partes. A primeira expõe o referencial teórico utilizado: a apropriação da economia política da comunicação e sua convergência com a teoria da estruturação. Deste modo, espera-se contribuir com o debate no campo da comunicação por meio de uma abordagem interdisciplinar com a teoria social contemporânea. Tal esforço se justifica pela importância da convergência entre distintos campos de saber. 
Com esse intuito, concentra-se na reflexão sobre a natureza do Estado moderno e no sistema interassociado de Estados-nação, enfatizando seu impacto para os sistemas de comunicação.

$\mathrm{Na}$ segunda parte, busca-se entender os argumentos através dos quais esta nova ordem deveria se constituir. Demonstra-se em que termos a legitimação da proposta recorre à noção de cidadania. Conjunto de valores e práticas institucionais, produzido durante a formação da modernidade e associado à expansão dos direitos individuais na luta contra as desigualdades estamentais, a definição de cidadania será contemporaneamente apropriada, no tema da comunicação, como questão a se considerar nas relações travadas entre Estados. A partir de tal constatação, demonstram-se quais argumentos o Relatório MacBride emprega no esforço de ultrapassar uma abordagem técnica sobre desenvolvimento, oferecendo uma dimensão moral ao assunto. A validação da afirmação reside na seguinte proposta: o desenvolvimento desigual representa a impossibilidade de realizar um direito específico. A conclusão encaminha o debate em direção a questões futuras.

\section{Economia política da comunicação, teoria da estruturação e cidadania}

A orientação teórica deste artigo parte da economia política da comunicação. Na concepção de Mosco (2009), tal enfoque se centra em três eixos. Mercantilização, o primeiro, busca compreender as diferentes maneiras de instrumentalização da cultura segundo a lógica de relações econômicas orientadas conforme a adequação meiosfins, própria ao sistema capitalista. Tal proposta foi extensamente desenvolvida. Emblemáticos foram os trabalhos voltados a compreender o processo de organização industrial do mercado de comunicação como decorrência de características caras a diferentes momentos do capitalismo (Bolaño e Brittos, 2007; Bustamante, 1999). 
Todavia, os demais eixos apontados por Mosco parecem ter sido explorados com maior parcimônia. Espacialização, o segundo, refere-se aos diferentes tipos de controle sobre tempo e espaço produzidos através de meios de comunicação. $O$ terceiro, estruturação, analisa o processo de reelaboração das estruturas a partir das possibilidades contidas na agência, num processo contínuo e aberto. Mosco refere tais temas a dois momentos do trabalho de Giddens ([1984] 1989; [1990] 1991), possíveis de expandir em direção à sua investigação sobre a formação do Estadonação (Giddens, [1985] 2001). Neste artigo, vai-se conectá-los ao debate sobre o processo de expansão da cidadania na modernidade, apropriando-se da obra de Marshall (1967), visando relacionar tal tema à discussão do processo de expansão do Estado-Nação.

No campo da comunicação, trabalhos produtivos (Barbalho, Fuser, Cogo, 2011) têm sido orientados pela abordagem de Cortina (2005) sobre o tema da cidadania. Sua proposta reside em construir alternativas para produzir um tipo de relacionamento entre indivíduo e sociedade num mundo marcado pelo individualismo hedonista, incapaz de produzir consenso normativo possível de orientar a vida cotidiana. A associação entre o tema do pertencimento e as demandas por racionalidade substantiva se afirmam, deste modo, como a principal contribuição necessária de produzir por meio da cidadania. Assim, a tarefa se divide em dois momentos: no primeiro, precisase definir que conteúdo, no âmbito da filosofia política, responderia como eixo responsável por gerar, em um segundo, ações procedimentais orientadas à produção de justiça redistributiva.

Tal problema constitui assunto importante de tratar. Porém, o enfoque aqui adotado remete a questões de outro tipo. Neste texto, opera-se com uma teoria capaz de descartar a necessidade dos agentes introjetarem disposições normativas, responsáveis por solucionar algum problema da ordem. Partindo do debate sobre estruturação, este 
artigo se concentra em compreender o processo de rotinização e de monitoramento reflexivo como elemento central à produção da vida social ${ }^{3}$. O tópico aqui analisado se expande do tema dos indivíduos em interação, direcionando-se à operação de um tipo de sistema social: o conjunto mutuamente orientado de Estados-nação. Interessa a forma como tais unidades políticas administrativas constroem a preocupação sobre a comunicação como assunto dotado de legitimidade, digno de ser tratado no plano da política internacional.

Aqui, encara-se a institucionalização do Estado moderno por meio da ampliação da eficiência de organizações, responsáveis por oferecer elementos para monitoração reflexiva das ações empreendidas por um extenso conjunto de indivíduos descolados no tempo-espaço. A teoria da estruturação se caracteriza por, através da apropriação da etnometodologia e da abordagem dramatúrgica, enfatizar a capacidade dos próprios indivíduos reproduzirem suas relações por meio de interações repercutidas. Torna-se importante distinguir tal abordagem de outras visadas, centradas em identificar demandas funcionais criadas sistemicamente e necessidades hipostasiadas responsáveis por direcionar a continuidade da vida social (Giddens, [1984] 1989; Cohen, [1987] 1999).

Abordar, na ação do Estado, os procedimentos e recursos dos quais os agentes são dotados permite concentrar-se na possibilidade de estabelecer formas de rotinização através da segurança ontológica em relacionamentos (Giddens, [1985] 2001). Se Giddens descarta a concepção parsoniana sobre a necessidade de introjetar disposições normativas responsáveis por guiar o ator, a agência capaz de tornar estas rotinas possíveis mostra intensa importância. Elas, e não tais disposições, garantem a continuidade da vida social. Tal discussão se conecta à forma como a teoria da estruturação entende o poder. Elemento endógeno aos relacionamentos humanos, compreendendo a vida social como processo intrinsecamente desigual, tal poder nunca 
pode ser totalmente ausente ou estar completamente concentrado, seja no que se refere a indivíduos ou a organizações.

A capacidade específica do Estado moderno reside em reter capacidade inédita de concentrar poder e de administrar a rotinização da vida social em grandes extensões descoladas no tempo-espaço. Merece destaque a organização de desencaixes e reencaixes nos quais sistemas peritos e fichas simbólicas possuem central relevância (Giddens, [1990] 1991). Deste modo, a concepção sobre política contida na teoria da estruturação mostra-se como não substantiva, numa visão que, retomando Weber ([1922] 1964), enxerga-a como a capacidade de administrar o controle e a disposição de recursos, monopolizando-os em certo território. O Estado se institui como um conjunto de organizações eficientes em organizar o prosseguimento da vida social devido à possibilidade de administrar elementos possíveis de influir na conduta dos homens.

Todavia, o Estado-nação como instrumento administrativo não pode existir em isolado, apresentando-se necessariamente como um sistema de vários Estados reflexivamente monitorados uns em relação aos outros. Ao concentrar-se sobre o tema da desigualdade, o Relatório MacBride versa sobre tal relacionamento. Contudo, toda defesa de posição demanda princípios de legitimação: neste processo, a conceituação sobre cidadania mostrará particular relevância. Processo ligado à diferenciação funcional e complexificação social (Marshall, 1967), encara-se tal questão por meio do desenvolvimento não evolutivo de distintos direitos civis, políticos e sociais, a partir da espiral aberta pela noção de igualdade. Decorrentes das possibilidades criadas pela adesão generalizada ao princípio da participação integral na comunidade política, direitos definem-se como a possibilidade de garantir algum tipo de oportunidade. O direito à propriedade, por exemplo, determina não a posse de um recurso, mas a probabilidade de obtê-lo. Deste modo, a cidadania se afirma como um processo, não 
como um resultado, exatamente por sua indefinição, a priori, sobre os efeitos possíveis de obter.

Defender a democratização da comunicação representa a probabilidade de proteger um direito social não apenas no relacionamento entre indivíduos ou grupos, mas entre nações distintas. Pressupõe a aplicação da noção de igualdade entre Estados, como um princípio amplo a partir da qual se podem propor ações distintas. Esclarecer através de que termos se outorga a possibilidade de desempenhar tal direito demanda entender os argumentos em pauta. Na próxima seção apresenta-se de que forma o entendimento sobre o direito à comunicação se estabelece como a possibilidade de interferir coletivamente em empreendimentos econômicos privados, gerando intervenções legitimadas por meio de expectativas amplas, sem a definição clara sobre os meios a utilizar para alcançar o objetivo. A situação é contraditória. Um direito social à comunicação produz expectativas infinitas, defendendo posturas difíceis de realizar concretamente. Apresentado como um fim legítimo, todavia, mesmo propostas das mais árduas e das menos realistas podem ser defendidas com probabilidade razoável de encontrar adesão.

\section{Trocas desiguais e a democratização da comunicação}

Não são poucos os temas abordados pelo Relatório MacBride. Seu texto enfatiza desde a necessidade da defesa de línguas nacionais até a importância de considerar as complexidades da administração de satélites geoestacionários, passando pela dificuldade em ampliar a produção de papel, insumo necessário para expandir a difusão de comunicação. A despeito de tal amplitude, podem-se apontar alguns eixos centrais em seus argumentos. Duas proposições atravessam todo o material ${ }^{4}$.

A primeira defende a criação de políticas de desenvolvimento para meios de comunicação, garantindo incentivos capazes de permitir um grau satisfatório 
de aprimoramento técnico (Unesco, [1980] 1983). Como toda atividade produtiva complexa, tal setor demanda investimentos significativos. Argumenta-se: com financiamento de porte, e somente assim, os diversos países, especialmente os subdesenvolvidos, teriam a chance de estabelecer uma infraestrutura mínima e indispensável. Há pouca novidade nesta abordagem: no contexto do pós-guerra, o auxílio para setores produtivos de nações periféricas adquiriu considerável peso político (Bielshowski, 2004). Recomendações sobre acordos bilaterais ou programas de apoio à industrialização interna não eram assunto desconhecido. Na comunicação, elas se consolidam por meio do Relatório MacBride e da sua defesa à criação de rádios e televisões locais, à multiplicação de jornais e à expansão na confecção de livros (Unesco, [1980] 1983).

Ao propor políticas à industrialização do setor de comunicação na periferia, o texto parece, consequentemente, tratá-lo de modo semelhante a atividades convencionais. Nestes termos, pouco distinguiria a indústria cultural do segmento químico ou siderúrgico, por exemplo. Defender a importância de criar uma estrutura para tal atividade recorre a argumentos sobre a necessidade de prover países subdesenvolvidos dos insumos tecnológicos voltados ao progresso técnico, como anteriormente já se havia feito com outras indústrias. Em intervenções desta natureza, a própria ONU possui papel central: basta recordar os nomes de Prebisch e da Cepal (Rodriguez, 1981). A conexão estabelecida pelo Relatório MacBride com a proposta de substituição de importações é direta. Aqui, todavia, a legitimação para a autoridade necessária no desempenho da tarefa parece ímpar.

A ênfase cepalina sobre as desigualdades nos termos de troca recorria a argumentos estritamente técnicos. Trata-se de uma releitura sobre conceitos da economia neoclássica, demonstrando, por noções caras à teoria, a inevitável deficiência do sistema de preços (Love, 1980). Todavia, o Relatório MacBride concede outro caráter 
à discussão. A segunda proposição salientada por este artigo indica o tema. Neste momento, defende a necessidade de equilibrar politicamente desigualdades intrínsecas a própria industrialização. Associar tal tema ao argumento da troca desigual e da descontinuidade entre centro e periferia, remete a afirmar que as mazelas observadas não se devem às contingências do setor de comunicação, mas, são próprias ao processo de expansão capitalista. Ao introduzir o debate sobre as trocas desiguais em relação à comunicação (Unesco, [1980] 1983), o Relatório MacBride se vê apto a propor não apenas ajustes pontuais, mas a construção de uma Nova Ordem Mundial de Comunicação e Informação.

Porém, sua justificativa em termos de interesses ideais necessita de um argumento poderoso para alcançar o impacto necessário. A proposta se solidifica e se expande a partir de uma elaborada construção conceitual. Apresenta-se tal desigualdade de trocas como fenômeno em dois níveis. O primeiro remete à comparação entre países com graus distintos de desenvolvimento econômico e social. Por hora, retorna-se a solo já pisado: o das disparidades macroestruturais. O segundo tópico, todavia, revela uma novidade. Aqui se estabelece a especificidade do Relatório. Tal tópico aponta para o descompasso não entre nações distintas, seu objetivo reside em identificar, no contato produzido entre meios e públicos, o caráter vertical nas indústrias de comunicação. Em tal cenário, o público se encontra passivo, sem possibilidade de intervenção real sobre tais indústrias.

Este relacionamento indica uma extrema desigualdade, semelhante, mas, distinta daquela anteriormente discutida. Tal público se vê exposto a uma série de temas definidos segundo critérios de importância, em descompasso com aqueles que ele mesmo deveria considerar relevantes. O relatório possui uma listagem de tais assuntos erroneamente desconsiderados, e os apresenta durante dois capítulos (Unesco, [1980] 1983). Assim, o processo de desenvolvimento responsável pela produção da 
infraestrutura necessária para a difusão de comunicação, parece culpado não apenas por criar uma relação desigual entre Estados. O modelo vertical de organização dos meios de comunicação impede a participação dos "povos" no processo de "desenvolvimento global" (Unesco, [1980] 1983, p. 341), impedindo a contrapartida necessária ao desenvolvimento: a melhoria nas "condições de vida" (Unesco, [1980] 1983, p. 339) do próprio homem, possível de se obter apenas por meio de outro modelo, mais horizontal.

Sem esta possibilidade, comprometer-se-ia o próprio processo de desenvolvimento. Dar-lhe direção, demanda compreender os rumos considerados mais precisos segundo o julgamento das próprias populações envolvidas, e não por meio de agendas internacionais impostas externamente. A compreensão do Relatório sobre o jornalismo, por exemplo, mostra-se emblemática nesta abordagem, pois, enfatiza-se intensamente esta profissão (Unesco, [1980] 1983). Por um lado, dever-se-ia encará-la como serviço público guiado por parâmetros éticos. Mas, por outro, apresentá-la assim, ultrapassaria a defesa pontual da atividade. Defender normas profissionais típicas a tal ofício permitiria se distanciar de temas impostos por modelos estrangeiros, verticais. Usualmente, julgam-se os acontecimentos cotidianos por meio de tais concepções. Os jornalistas deveriam contribuir na produção horizontal da comunicação, reequilibrando as trocas desiguais. Escolas de formação, associações profissionais e instrumentos de proteção a tal categoria - todos fatores de desenvolvimento - tornamse imprescindíveis. Contudo, tal faceta da desigualdade de acesso à comunicação se torna digna de considerar por razões mais amplas: sua utilidade como solução para o subdesenvolvimento de Estados.

Este imperativo se apropria da tentativa de dar novo significado a um tema já discutido pela comunidade internacional desde o primeiro momento do pós-guerra. A proposta conhecida como o Livre Fluxo de Informação, defesa do combate às barreiras 
políticas para a comunicação, demandava a abertura de qualquer mercado à circulação de conteúdo, endossando a liberdade comercial de imprensa. O Relatório propõe inverter este argumento. Trata-se de considerar, nas desigualdades entre nações, um impedimento aos preceitos defendidos pela própria proposta do livre fluxo. Necessariamente incompleto, este projeto seria plenamente realizado ao encarar tais descontinuidades em sua real dimensão. De forma irremediável, estas diferenças limitam, através do descompasso econômico, a realização não apenas do processo de aprimoramento material: elas restringem um direito.

Afirmar tais direitos parece ser o tema central do Relatório. Não apenas diferenças econômicas entre países nem limites políticos à circulação de conteúdo, o desenvolvimento desigual surge como enclave a um direto à comunicação (Unesco, [1980] 1983). Introduz-se, assim, um poderoso mecanismo de legitimidade para incentivo ao desenvolvimento nacional destes setores. $O$ peso de tal noção de direito permite transformar um projeto voltado a aprimorar condições materiais, tornando-o capaz de ultrapassar demandas por auxílio financeiro ou apoio internacional. Definida como direito básico ao homem, a comunicação se constitui como uma necessidade indispensável de aprimorar.

Deste modo, questionar a organização econômica das indústrias culturais e intervir em corporações de países desenvolvidos transforma-se em empreitada legítima. A proposta de maior impacto no Relatório reside em reavaliar a forma pela qual se estabelecem tais negócios. O texto não se pronuncia sobre quais ações adotar, a fim de restringir tal poder, a não ser de modo lateral. Uma preocupação central reside no caráter global destes empreendimentos (Unesco, [1980] 1983), seguindo o ritmo de expansão do capitalismo. No texto, apresentam-se poucas propostas concretas, mas defender limites à atividade econômica ou ao aprimoramento técnico de tais corporações procede de um poderoso argumento: acumulação e inovação devem se 
transformar em instrumento capaz de permitir o exercício de tal direito social, ao invés de se justificar como um fim em si (Unesco, [1980] 1983).

Tais assuntos se mostram como um tema a considerar na monitoração reflexiva entre nações, em termos das rotinas a partir das quais se obtém formas de prosseguir com a vida social. Os valores defendidos envolvem temas com forte carga simbólica, invocando imagens caras à modernidade. Sua defesa remete a uma noção de cidadania como relação estabelecida com base nas possibilidades contidas no valor de igualdade. Uma diferença central parece presente. A busca por direitos durante o processo de formação da modernidade prezou pela dissolução de privilégios estamentais e garantia de igualdade universal (Bendix, [1964] 1996). Como proposto no Relatório, os direitos afirmados no âmbito das relações internacionais se referem ao convívio entre Estados em busca de oportunidades que lhes permitam exercer influência sobre a forma como nações, dentro de um sistema inter-relacionado, administram seus recursos. Ao examinar instituições administrativas burocratizadas de grande porte em ação, presencia-se uma relação diferente daquela em que se observam grupos sociais em busca de autoafirmação.

\section{Conclusão}

Neste artigo, apresentou-se o Relatório MacBride como uma tentativa de introduzir um tema novo com tópicos a considerar no relacionamento entre nações distintas. Seu conteúdo se afirma como uma inquietação de âmbito global, relativa ao posicionamento de Estados autônomos uns em relação aos outros. Assim, a ideia de trocas desiguais e a tentativa de atribuir um conteúdo político às desigualdades econômicas recorrem a uma noção de cidadania possível de adquirir extrema importância.

Daí em diante, o projeto se torna negociar com pautas preexistentes na agenda mundial. A resignificação da proposta de livre fluxo, criticando-a pela liberdade incompleta que 
propõe, busca dar nova dimensão a tais relações internacionais. As desigualdades econômicas poderiam ser superadas por meio de investimento no desenvolvimento endógeno de um setor de comunicação com maior autonomia, capaz de instituir suas prioridades através de temas caros ao desenvolvimento de seus próprios países.

Ao descumprir tal objetivo, se violaria um direito essencial. $\mathrm{O}$ uso de tais noções estabelece um princípio de intensa relevância na relação entre tais nações. Aqui, discutiu-se tal questão através de uma perspectiva marcada pela convergência teórica entre a economia política da comunicação, o debate sobre cidadania e a teoria da estruturação. $\mathrm{O}$ objetivo foi entender como se introduz um novo recurso específico: a discussão política simultânea sobre desenvolvimento e direito, num debate de amplas repercussões.

\section{REFERÊNCIAS}

BARBALHO, Alexandre; FUSER, Bruno; COGO, Denise. (Org.) Comunicação e cidadania: questões contemporâneas. Fortaleza: Demócrito Rocha, 2011.

BENDIX, Reinhard. Construção social e cidadania: estudos de nossa ordem social em mudança. São Paulo: Edusp, 1996.

BIELSCHOWSKY, Ricardo. Pensamento econômico brasileiro: o ciclo ideológico do desenvolvimento. Rio de Janeiro: Contraponto, 2004.

BOLAÑO, César; BRITTOS, Valério. A televisão brasileira na era digital. São Paulo: Paulus, 2007.

BUSTAMANTE, Enrique. La televisión económica. Barcelona: Gedisa, 1999.

CARLSSON, Ulla. The Rise and Fall of NWICO. From a vision of international regulation to a reality of multilevel governance. Nordicom Review, v. 24, n. 2, pp. 31-68, 2003.

COHEN, Ida. Teoria da Estruturação e Práxis Social. GIDDENS, Anthony; TURNER, Jonathan. (Org.). Teoria social hoje. São Paulo: UNESP, 1999.

CORTINA, Adela. Cidadãos do mundo: para uma teoria da cidadania. São Paulo: Loyola, 2005.

GIDDENS, Anthony. A constituição da sociedade. São Paulo: Martins Fontes, 1989.

. O Estado-Nação e a violência. São Paulo: Edusp, 2001. 
GIDDENS, Anthony. As consequências da modernidade. São Paulo: UNESP, 1991.

LOVE, Joseph. Raúl Prebisch and the origins of the doctrine of unequal exchange. Latin American Research Review, v. 15 , n. 3, pp. 45-72, 1980.

MARSHALL, Thomas. Cidadania, classe social e status. Rio de Janeiro: Zahar, 1967.

MASTRINI, Guillermo; CHARRAS, Diego de. Twenty years mean nothing. Global Media and Communication, v. 1, n. 3, pp. 273-288, 2005.

MOSCO, Vincent. The political economy of communication. London: Sage, 2009.

PASQUALI, Antonio. The south and the imbalance in communication. Global Media and Communication, v. 1, n. 3, pp. 289-300, 2005.

RODRIGUEZ, Octavio. A teoria do subdesenvolvimento da Cepal. Rio de Janeiro: Forense Universitária, 1981.

UNESCO. A documentary history of a new world information and communication order seen as an evolving and continuous process, 1975-1986. Paris: UNESCO, [s.d.].

UNESCO. Um mundo e muitas vozes: comunicação e informação na nossa época. Rio de Janeiro: FGV, 1983.

WEBER, Max. Economía y sociedad: esbozo de sociología comprensiva. México: Fondo de Cultura Económica, 1964.

\section{NOTAS}

1 O presente trabalho foi realizado com o apoio da CAPES, entidade do Governo Brasileiro voltada para a formação de recursos humanos.

2 Para uma avaliação completa de todo o processo de instituição de tal debate, ver Unesco (s.d.).

3 Alguns conceitos devem ser esclarecidos. Define-se monitoração reflexiva como a capacidade sempre intencional de dar prosseguimento ao curso das ações a partir de habilidades desenvolvidas pelos agentes. A despeito dos princípios estruturais em relação ao qual se define, a especificidade do Estado moderno reside em oferecer elementos a partir dos quais o relacionamento entre os indivíduos, assim como a administração exercida pelo próprio Estado sobre estes mesmos atores, podem ser estabelecidos em extensões mais amplas de tempo-espaço, descoladas das relações de copresença. Monitoração reflexiva se refere, assim, à capacidade de dar prosseguimento à vida social, a partir dos recursos operacionalizados por uma consciência prática capaz de tratar os elementos do cotidiano como autoevidentes.

4 Observa-se uma terceira questão, de importância lateral. Consiste em considerar a relevância dos mecanismos tradicionais de comunicação e a necessidade de associá-los às indústrias culturais, na expectativa de retirar o melhor de ambos. Tal postura pressupõe as relações tradicionais como instrumento útil na produção de canais plurais de diálogo, e não como um empecilho legado pela tradição (Unesco, [1980] 1983). 